\title{
New Method of Controlling Sugarcane Smut using Flutriafol Fungicide
}

\author{
Shamsul A. Bhuiyan and Barry J. Croft, Sugar Research Australia (SRA), Woodford, QLD 4514 Australia; Glen R. Tucker, SRA,
} Woodford, and Crop Care Australasia, Unit 15, Murarrie, QLD 4172, Australia

\begin{abstract}
Bhuiyan, S. A., Croft, B. J., and Tucker, G. R. 2015. New method of controlling sugarcane smut using flutriafol fungicide. Plant Dis. 99:1367-1373.

Sugarcane smut, caused by Sporisorium scitamineum, is one of the most devastating diseases of sugarcane worldwide. Triazole fungicides such as propiconazole and triadimefon have been routinely used as dip treatments to protect seed-cane (stalk cuttings) from infection by sugarcane smut fungus. However, dip treatments can be applied only to mother stock (nursery) planting materials because of the logistics of dipping large quantities of seed-cane and it is difficult to dispose of the large volumes of waste fungicide solution in an environmentally safe manner. There was a need for a new fungicide that can be applied using more practical methods. The efficacy of flutriafol fungicide to control smut was evaluated in inoculated and infected stalks of a highly susceptible cultivar using various application methods. In a 2007 experiment, flutriafol fungicide was equally effective or better in controlling sugarcane smut as a dip than were two fungicides, propiconazole and triadimefon, registered in Australia. In 2009, two experiments determined the effectiveness

of flutriafol when applied by mixing with fertilizer or spraying on the seed-cane at planting. All fungicide treatments significantly suppressed smut in one experiment but, in the second experiment, flutriafolfertilizer mix treatments were ineffective. In 2010, two experiments verified the efficacy and effective rates of flutriafol against sugarcane smut when applied through existing spray equipment designed to spray fungicide on cuttings as they drop into the planting furrow on a commercial planter. Area under the disease progress curve values of smut incidence were reduced significantly to 47 and $56 \%$ with low $\left(125 \mathrm{~g}\right.$ a.i. ha $\left.{ }^{-1}\right)$ and high $\left(375 \mathrm{~g}\right.$ a.i. $\left.\mathrm{ha}^{-1}\right)$ application rates, respectively, in both experimental sites compared with the inoculated control plots. Sugar yield increased by 46 to $65 \%$ in one experiment and 157 to $203 \%$ in the second experiment compared with the inoculated control. This research formulated a more practical method of application of flutriafol and suggests greater applications of this fungicide for the management of sugarcane smut.
\end{abstract}

Sugarcane smut, caused by the fungus Sporisorium scitamineum (Syd.) M. Piepenbr., M. Stoll \& Oberw., formerly called Ustilago scitaminea (24), is an important disease worldwide (9). It was reported for the first time Australia in the Ord River Irrigation Area of Western Australia in 1998 (10), and then discovered in Queensland, the major Australian sugarcane-growing area, in June 2006 (11). Sugarcane smut can cause significant yield loss when susceptible cultivars are planted (9). In Louisiana, there is 0.6 to $0.7 \%$ yield loss for every $1 \%$ increase in diseased plants (13). In Australia, yield losses of up to $62 \%$ were estimated if susceptible cultivars were planted (17).

Sugarcane smut can be managed effectively if resistant cultivars are planted (9). Other control measures that are used in conjunction with resistant cultivars are hot-water treatment and fungicide application to seed-cane (stalk cuttings), and rogueing of infested stools or plow out of infested crops (9). Rouging of diseased plants will slow spread of the disease and has been used in countries with low labor cost (16) but is not commercially feasible in Australia. Fungicides have been used in Australia and other countries to protect seedcane from infection with sugarcane smut $(2,6)$. Fungicides have been applied to seed-cane as a cold-water dip or the fungicide has been added to hot-water treatment tanks that are used to eliminate systemic infections of smut and other diseases from seed-cane so that both the curative and protectant treatments are applied simultaneously. LeeLovick (16) listed different organomercury and organochlorine fungicides that have some efficacy for controlling smut in seed-cane. Two triazole fungicides, triadimefon and propiconazole, are effective in controlling sugarcane smut in seed-cane $(3,9)$. In Australia, Bhuiyan et al. (6) found that the triazole fungicides propiconazole,

Corresponding author: S. Bhuiyan; E-mail: sbhuiyan@ sugarresearch.com.au

*The $\boldsymbol{e}$-Xtra logo stands for "electronic extra" and indicates that one supplementary figure is published online.

Accepted for publication 13 January 2015.

http://dx.doi.org/10.1094/PDIS-07-14-0768-RE

(C) 2015 The American Phytopathological Society triadimefon, and cyproconazole and the strobulirin fungicide azoxystrobin were effective when applied as dip treatments. Propiconazole and triadimefon are registered to use as dip treatment to control sugarcane smut in Australia. Sugarcane is planted with stalk cuttings of 200 to $300 \mathrm{~mm}$ in length at 5 to 10 tons of cuttings per hectare. The cuttings are either cut from whole stalks that are fed into a planting machine in the field or are cut by a sugarcane harvester and tipped into a planting machine that feeds the cuttings into the planting furrow. Fungicide dip treatment of large tonnages of sugarcane has some practical problems: (i) the logistics of the dip treatments, which are limited to the treatment of seed-cane in nursery mother plots; (ii) large tanks of at least 5,000- to 10,000-liter capacity are required to treat the seed-cane; and (iii) disposal of the waste fungicide after use by an environmentally accepted method is expensive.

Flutriafol fungicide is registered in Australia to control fungal diseases of grain and cereal crops. The fungicide is effective in controlling diseases of canola and cereals when applied by mixing with fertilizer or as a foliar spray $(4,15,18)$. Research has indicated that flutriafol is more mobile within plants than other triazole fungicides $(19,22)$. We $(7)$ have shown that this fungicide is effective in controlling pineapple sett rots, caused by Ceratocystis paradoxa, of sugarcane when sprayed on the seed-cane at planting. There was no information available on the efficacy of this fungicide in controlling sugarcane smut.

We aimed to determine the efficacy of the fungicide flutriafol in controlling sugarcane smut when applied by mixing with fertilizer or as a spray on the seed-cane at planting using the spray equipment available to all sugarcane planters in Australia to control pineapple sett rot.

\section{Materials and Methods}

Experiment 1: Efficacy of flutriafol in controlling smut when applied as a dip. An experiment was established at Sugar Research Australia (SRA, former BSES), Smut Research Farm (SRF), Bundaberg $\left(\mathrm{S} 25.0^{\circ}, \mathrm{E} 152.2^{\circ}\right)$ to determine the efficacy of flutriafol compared with the two fungicides (propiconazole and triadimefon) already registered in Australia for treatment of sugarcane smut as a dip treatment.

All experiments were conducted using the highly smut-susceptible sugarcane 'Q205' '. Material was sourced from SRA Bundaberg, 
which had a low incidence of smut at the time of collection. No smut was observed in the source plot. The sugarcane stalks were cut into one-bud cuttings using an electric saw and cleaned of extraneous matter by dipping in clean tap water.

Fungicides, treatments, and application. Three fungicidestriadimefon (Turret; NuFarm Australia Limited, Australia), propiconazole (Throttle; NuFarm Australia Limited), and flutriafol (Sinker; Crop Care Australasia, Australia) — were used. Triadimefon and propiconazole were applied using four rates; zero, half, full, and double of the registered rates for the control of smut (Table 1). We used the same rates of flutriafol fungicide as for propiconazole. One-bud cuttings were dipped into fungicide solution for $5 \mathrm{~min}$ at ambient temperature. A nonionic surfactant Agral (nonyl phenol ethylene oxide condensate at $600 \mathrm{~g} \mathrm{liter}^{-1}$; Syngenta Australia) was mixed with the dip at the rate of $0.50 \mathrm{ml}$ liter $^{-1}$. After the fungicide application, the cuttings were allowed to dry at ambient temperature for approximately an hour before being inoculated with a smut spore suspension. A noninoculated control with no fungicide was also included. Spores of S. scitamineum were collected from mature smut sori on Q205 ${ }^{\mathrm{A}}$ by cutting the sorus 10 to $20 \mathrm{~cm}$ below the top visible dewlap (a band of membranous tissue between the leaf sheath and the leaf blade) and placing it in a plastic bag. The sori were then spread out in a tray and maintained in a drying cabinet at $12 \pm 1^{\circ} \mathrm{C}$ and $12 \pm 1 \%$ relative humidity for 2 weeks. Spores were collected from the sorus by scraping and subsequent sieving through a nylon net (1 by $1 \mathrm{~mm}$ ) to remove plant material. Spores were then stored in a sealed container at $4^{\circ} \mathrm{C}$ until use. The fungicide-treated cuttings were dipped in a spore suspension of approximately $5 \times 10^{6}$ spores $\mathrm{ml}^{-1}$ in deionized water with a few drops of Tween 20 for $10 \mathrm{~min}$. After inoculation, the cuttings were maintained in a chamber at $31^{\circ} \mathrm{C}$ overnight and covered with a plastic tarpaulin to maintain high humidity (8). Germination of the spores was checked before inoculation, and no spores were used which had $<90 \%$ germination. The cuttings were planted on 22 November 2007 in five replicates in a randomized complete-block design. Each plot consisted of 12 one-bud cuttings planted in a 6-m plot with a $0.75-\mathrm{m}$ gap between plots. The total number of plants (delineated as a stump with multiple tillers) and plants showing smut sori in each plot were recorded 49, 72, and 174 days after inoculation (DAI). A plant was considered to be infected if any tiller within the plant showed a sorus.

Experiments 2 and 3: Efficacy of flutriafol when applied with fertilizer or sprayed over the cuttings in the row at planting. Two experiments were initiated in 2009 to evaluate the potential of flutriafol for the control of smut by methods that are more practical for field application than were used in experiment 1.

Stalks of susceptible Q205 ${ }^{\mathrm{A}}$ with no visible symptoms of smut were hot-water treated at $52^{\circ} \mathrm{C}$ for $30 \mathrm{~min}$ to eliminate any systemic smut infection. Stalks were then cut into two-bud cuttings using an electric saw before inoculation, as described above. A noninoculated control treatment was included.

Fungicide application and treatment. Seven rates $(0,125,187.5$, $250,312.5$, and $500 \mathrm{~g}$ a.i. $\mathrm{ha}^{-1}$ ) of flutriafol fungicide were applied using three application methods: (i) mixed with fertilizer, (ii) wide spray (approximately $15 \mathrm{~cm}$ spray band) over the cuttings in the furrow at planting, and (iii) narrow spray (approximately $5 \mathrm{~cm}$ spray band) over the cuttings in the furrow at planting with a knapsack sprayer after placing the cuttings in the furrow. Special care was taken not to cover cuttings with soil during spraying. Agral 600 adjuvant was mixed with the fungicide at $0.5 \mathrm{ml} \mathrm{liter}^{-1}$ prior to spraying. For the fertilizer mix treatments, the required amount of fungicide was added to deionized water, and then sprayed over the fertilizer di-ammonium phosphate (DAP; $18 \mathrm{~N}: 20 \mathrm{P}: 0 \mathrm{~K}: 1.2 \mathrm{~S}$ ), and mixed thoroughly by tumbling in a plastic jar. The flutriafolfertilizer mix was allowed to dry overnight inside a fume hood The flutriafol-fertilizer mix was added to the furrow at $200 \mathrm{~kg} \mathrm{ha}^{-1}$ and covered with a few millimeters of soil before the cuttings were placed in the furrow. The same amount of DAP fertilizer without fungicide was added to the furrows of other treatments to maintain uniformity of nutrients levels across the treatments.

Experiment 2 was established at SRA Bundaberg (S 24.5 ${ }^{\circ}$, E $152.2^{\circ}$ ) in a red volcanic soil in early spring on 4 September 2009 and completed on 21 April 2010. Experiment 3 was established at SRA SRF in a sandy soil in summer on 1 December 2009 and completed on 7 June 2010. The experiments were planted with a two-bytwo factorial randomized complete-block design with five replicates. Each plot was 5 by $1.5 \mathrm{~m}$ with a 1 -m gap between plots, and 10 twobud cuttings were planted in each plot.

The two experiments were inspected for smut symptoms every 2 weeks or monthly, depending on the expression of smut symptoms. The total number of plants and plants showing smut sori in each plot were recorded.

Experiments 4 and 5: Efficacy of flutriafol when applied at planting using a commercial planter. Two experiments were established to determine the efficacy and effective rates of flutriafol against sugarcane smut when applied through existing pineapple sett rot control spray equipment on a commercial planter.

Stalks of Q205 ${ }^{\mathrm{A}}$ were sourced from a smut-free block. Stalks were then hot-water treated at $52^{\circ} \mathrm{C}$ for $30 \mathrm{~min}$ to eliminate any systemic infection by S. scitamineum, and dipped into a smut spore suspension for $10 \mathrm{~min}$. After inoculation, the stalks were placed in a chamber at $31^{\circ} \mathrm{C}$ for $24 \mathrm{~h}$ for the Bundaberg experiment and $48 \mathrm{~h}$ for the Mackay experiment. Flutriafol fungicide was applied using five rates $(0,125$, 187.5, 250, and $375 \mathrm{~g}$ a.i ha ${ }^{-1}$ ). Propiconazole at the rate of $250 \mathrm{~g}$ a.i. $\mathrm{ha}^{-1}$ was included in these experiments for comparison. A noninoculated control was included in both experiments.

Fungicides were applied through a standard spray system used for control of pineapple sett rot fitted to a whole-stalk sugarcane planter (model 401; Cane Country, Australia). The spray system was calibrated to measure the volume of fungicide solution applied per hectare and the rates of the fungicides were adjusted appropriately. Four even-fan nozzles (type CORMACK 03 F110; Hardi Australia) were set up in two pairs at $90^{\circ}$ angles to give complete coverage of the cuttings. The nozzles applied 5.7 liters $100^{-1} \mathrm{~m}$ of row or 380 liters $\mathrm{ha}^{-1}$.

Table 1. Efficacy of flutriafol fungicide compared with two registered fungicides (propiconazole and triadimefon) in controlling sugarcane of smut at 77 and 174 days after inoculation (DAI) in experiment $1^{z}$

\begin{tabular}{|c|c|c|c|}
\hline Treatment & Rate (g a.i. 100 liters $^{-1}$ ) & 77 DAI (\% smut) & 174 DAI (\% smut) \\
\hline Flutriafol & 25 & $5.2 \mathrm{a}$ & $14.0 \mathrm{a}$ \\
\hline Flutriafol & 50 & $7.2 \mathrm{a}$ & $14.1 \mathrm{a}$ \\
\hline Propiconazole & 50 & $7.6 \mathrm{a}$ & $14.9 \mathrm{ab}$ \\
\hline Flutriafol & 12.5 & $7.1 \mathrm{a}$ & $17.3 \mathrm{abc}$ \\
\hline Noninoculated control & $\ldots$ & $22.2 \mathrm{~b}$ & $20.1 \mathrm{abc}$ \\
\hline Triadimefon & 100 & $7.1 \mathrm{a}$ & $23.1 \mathrm{abc}$ \\
\hline Propiconazole & 25 & $5.1 \mathrm{a}$ & $23.9 a b c$ \\
\hline Propiconazole & 12.5 & $5.2 \mathrm{a}$ & $26.8 \mathrm{abc}$ \\
\hline Triadimefon & 50 & $5.9 \mathrm{a}$ & $28.7 \mathrm{c}$ \\
\hline Triadimefon & 25 & $6.2 \mathrm{a}$ & $31.1 \mathrm{c}$ \\
\hline Inoculated control & $\ldots$ & $18.5 \mathrm{~b}$ & $55.9 \mathrm{~d}$ \\
\hline
\end{tabular}

${ }^{\mathrm{z}}$ Each data point is the mean of five replications. Means within a column followed by the same letter are not significantly different using Fisher's least significant difference test $(P<0.05)$. 
Agral 600 was mixed with all fungicide treatments at $0.5 \mathrm{ml} \mathrm{liter}{ }^{-1}$. Experiment 4 was established at the SRA Bundaberg in a red volcanic soil on 14 September 2010 and harvested in October 2011. Experiment 5 was established at the SRA Mackay (S 21.1 ${ }^{\circ}$ E $\left.149.1^{\circ}\right)$ in August 2010 in a podozolic soil and harvested on 2 November 2011. Both experiments were set up with a randomized completeblock design with five replicates. Each plot comprised 3 rows by $15 \mathrm{~m}$, including a 1-m gap between plots. Row spacing was $1.5 \mathrm{~m}$ in Bundaberg and $1.6 \mathrm{~m}$ in Mackay.

Disease assessment and harvesting. The incidence of smut was recorded at 2-weekly or monthly intervals, depending on the expression of disease. Observations were continued until May and June 2011 for Mackay and Bundaberg, respectively. Ratings were discontinued when secondary smut spread, indicated by the development of smut in noninoculated control plots and production of smut sori on side shoots on standing stalks, was widespread within the trial. Experiments were harvested on 12 October and 2 November 2011 for Bundaberg and Mackay, respectively. Weight of the harvested canes in a row was recorded during harvesting with an automatic weighing machine fitted with the haulout (a tractor fitted with a trailer to collect harvested canes), and cane yield (tons) per hectare was estimated by the formula cane yield $=[W \times(10,000 / R)] /(L \times 1,000)$, where $W=$ weight of the canes in each row $(\mathrm{kg}), R=$ row spacing $(\mathrm{m})$, and $L=$ row length $(\mathrm{m})$. Percentage of sugar in the harvested canes (called commercial cane sugar [CCS]) and fibers were determined by a SpectraCane machine (Biolab Limited, NZ). Sugar yield (tons) per hectare was determined by using the formula (cane yield $\left.\mathrm{ha}^{-1} \times \mathrm{CCS}\right) / 100$.

Data analysis. The incidence of the smut per plot was calculated as (diseased plants/total number plants) $\times 100$.

Area under disease progress curve (AUDPC) was calculated according to Shaner and Finney (21) as $A U D P C=\sum_{i=1}^{n_{i-1}}\left(\frac{Y_{i}+Y_{i+1}}{2}\right)\left(T_{i+1}-T_{i}\right)$, where $Y_{i}=$ disease incidence at the $i$ th observation, $T_{i}=$ time (day) of the $i$ th observation, and $n=$ total number of observations. A linear mixed model was fitted to all datasets using Proc Mixed in SAS (version 9.4; SAS Institute, Cary, NC). For Experiment 1, fungicides (treatment), rates of fungicide, day after inoculation (DAI), and their interaction were treated as fixed effects. On the other hand, block (replication) and the error term (residual) were treated as random effects. Correlated measurements among the unequally spaced DAI were accounted for by fitting a spatial power correlation structure. Because no smut was observed during the first inspection (49 DAI), data were not included during the analysis. For the other experiments, all possible interactions of the fixed effects were also included in the model. Degrees of freedom were adjusted using the Kenward-Roger method (14) and normality of residuals was tested using Proc Univariate of SAS. A logit transformation was applied to the experiment 1 data prior to analysis (26) as proportion $=($ total diseased plant +0.5$) /($ total plant - total diseased plant +0.5$)$. Estimated logit values were then back-transformed before presenting in the result. For the appropriate significant factors, protected-mean comparisons of all possible pairwise differences of the means were tested at $\alpha=0.05$, using Fisher's protected least significant difference test. PDMIX800 SAS Macro was used to convert mean separation output to letter groupings (20).

\section{Results}

Experiment 1. In experiment 1, there were significant differences in smut incidence among treatments and inspection times (DAI) and significant interactions among treatments and times of inspection (Table 2). There were no significant differences among the different rates of the fungicides and no significant interaction between treatments and rates and rates and time of inspection.

No smut was observed during the first inspection at 49 DAI. At 77 DAI, all fungicide treatments had significantly less smut than the inoculated control and the noninoculated control but there were no differences among fungicide treatments. At 174 DAI, all three fungicides had significantly lower smut incidence than the inoculated control at all rates (Table 1). However, two rates of flutriafol (25 and $50 \mathrm{~g}$ a.i. 100 liters $\left.^{-1}\right)$ and the highest rate of propiconazole (50 g a.i. 100 liters $^{-1}$ ) had significantly less smut than the two lower rates of triadimefon.

The symptoms observed at 77 DAI were mainly smut sori on primary or secondary shoots, which is typical of primary infection (infection of the planted buds). However, at 174 DAI, there was a mixture of primary infection and secondary infection (from surrounding infected fields and primary sori) indicated by the presence of sori on side shoots of the standing stalks. Due to the limited disease assessment events, it was not possible from this experiment to determine the length of protection

Experiments 2 and 3. Experiment 2 was planted in early spring and the temperatures ranged from 10 to $35^{\circ} \mathrm{C}$, with a mean of $22^{\circ} \mathrm{C}$ for the first 3 months after planting (Supplementary Fig. S1). Mean relative humidity for this period was $48 \%$, with a range of 51 to $65 \%$. There were significant differences among different rates of fungicide applications and different application methods and their interactions (Table 3). All rates of flutriafol with both narrow and

Table 2. Type 3 test of fixed effects for the field experiment, treatments, rates, and days after inoculation (DAI) and their interactions from SAS Proc mixed-model analysis

\begin{tabular}{|c|c|c|c|c|}
\hline Effect & Numerator DF & Denominator DF & $F$ value & $\operatorname{Pr}>F$ \\
\hline Treatment & 3 & 40 & 10.5 & $<0.0001$ \\
\hline Rate & 2 & 40 & 1.41 & 0.2567 \\
\hline DAI & 1 & 44 & 60.22 & $<0.0001$ \\
\hline Treatment $\times$ rate & 4 & 40 & 0.41 & 0.7992 \\
\hline Treatment $\times$ DAI & 3 & 44 & 3.43 & 0.0249 \\
\hline Rate $\times$ DAI & 2 & 44 & 1.61 & 0.2117 \\
\hline Treatment $\times$ rate $\times$ DAI & 4 & 44 & 0.23 & 0.9197 \\
\hline
\end{tabular}

Table 3. Type 3 test of fixed effects for the field experiment, treatments, and rates and their interactions from SAS Proc mixed-model analysis ${ }^{\mathrm{y}}$

\begin{tabular}{|c|c|c|c|c|c|c|c|c|}
\hline \multirow[b]{3}{*}{ Effects $^{z}$} & \multicolumn{4}{|c|}{ Experiment 2} & \multicolumn{4}{|c|}{ Experiment 3} \\
\hline & \multicolumn{2}{|c|}{164 DAI } & \multicolumn{2}{|c|}{ AUDPC } & \multicolumn{2}{|c|}{187 DAI } & \multicolumn{2}{|c|}{ AUDPC } \\
\hline & $F$ value & $\operatorname{Pr}>\boldsymbol{F}$ & $F$ value & $\operatorname{Pr}>F$ & $F$ value & $\operatorname{Pr}>F$ & $F$ value & $\operatorname{Pr}>\boldsymbol{F}$ \\
\hline Rate & 4.78 & 0.0003 & 6.61 & $<0.0001$ & 15.26 & $<0.0001$ & 67.63 & $<0.0001$ \\
\hline Treatment & 20.1 & $<0.0001$ & 23.62 & $<0.0001$ & 2.76 & 0.0692 & 5.55 & 0.0056 \\
\hline Rate $\times$ treatment & 2.18 & 0.0207 & 3.46 & 0.0004 & 1.2 & 0.2949 & 1.09 & 0.3773 \\
\hline
\end{tabular}

\footnotetext{
${ }^{\mathrm{y}} \mathrm{DAI}=$ days after inoculation, when maximum disease suppression occurred, and AUDPC $=$ area under disease progress curve for the whole trial period
}

${ }^{\mathrm{z}}$ Treatment $=$ spray application methods (narrow spray, wide spray and fertilizer-mix) 
wide spray application methods had significantly reduced smut incidence at 164 DAI and AUDPC for the duration of the experiment compared with inoculated control and fertilizer-mix (Table 4). Flutriafol mixed with the fertilizer did not reduce smut. All fungicidetreated plots using narrow and wide spray methods had very little $(<10 \%)$ or no smut for more than 5 months (164 DAI) (Fig. 1A). After 5 months of inoculation, smut incidence increased sharply in all treatments, including in the noninoculated control, and smut sori were observed on side shoots and tillers as secondary infections.

Experiment 3 was planted in early summer and the temperatures ranged from 17 to $37^{\circ} \mathrm{C}$, with a mean of $26^{\circ} \mathrm{C}$ for the first 3 months of planting. Mean relative humidity for this period was $40 \%$, with a range of 37 to $44 \%$. Significant differences of smut incidence were observed among rates of fungicide applications (although no differences among mode of applications) and the interactions between application rates and mode application at 187 DAI (Table 3), whereas significant differences of AUDPC values were observed among application rates and mode of application but no significant differences between their interactions. In experiment 3 , all rates of flutriafol applied as a wide or narrow spray and the flutriafol-fertilizer mixes significantly reduced smut incidence until the end of the trial period (187 DAI) compared with the inoculated control (Table 4). No significant differences were observed in AUDPC smut incidence values among rates or modes of application; all rates and modes of applications were equally effective. Very low $(<10 \%)$ or no smut was observed in all treatments, including the noninoculated control, over 6 months (187 DAI), whereas smut rapidly increased in inoculated control plots from $60 \mathrm{DAI}$ and reached over 50\% within 6 months (Fig. 1B).

Experiments 4 and 5. In both experiments (Bundaberg and Mackay), the AUDPC values of incidence were significantly lower in all fungicide-treated plots compared with the inoculated control (Table 5). AUDPC values of smut incidence were significantly lower for flutriafol at rates of 250 and $275 \mathrm{~g}$ a.i. ha $^{-1}$ compared with propiconazole $\left(250 \mathrm{~g}\right.$ a.i. $\left.\mathrm{ha}^{-1}\right)$ in experiment 4 . In experiment 5 , three rates $\left(187.5,250\right.$, and $375 \mathrm{~g}$ a.i. $\left.\mathrm{ha}^{-1}\right)$ of flutriafol provided significantly better control of smut compared with the propiconazole treatment.
Smut incidence remained significantly lower in all fungicidetreated plots compared with the inoculated control in both experiments until the end of the assessment period (Fig. 2). The disease incidence remained constantly low $(<20 \%)$ in treated plots to 160 days in both experiments, and increased rapidly afterward. At the same time, smut incidence started to increase in the noninoculated control plots, indicating secondary infection.

All rates of flutriafol and propiconazole significantly increased cane and sugar yields compared with the inoculated controls in both experiments (Tables 6 and 7). Cane yield increased by 43to $62 \%$ and sugar yield increased by 46 to $65 \%$ in the fungicide-treated plots compared with the inoculated control in experiment 4 . In experiment 5 , the fungicide treatments increased cane yield by 148 to $185 \%$ and sugar yield by 157 to $203 \%$. All rates of fungicide treatments, except flutriafol at $150 \mathrm{~g}$ a.i. ha ${ }^{-1}$, increased sugar content compared with the inoculated control in experiment 5 but there were no significant differences in sugar content in experiment 4 among treatments. There were no significant differences in fiber content among any treatments at both sites. Propiconazole gave increases in cane and sugar yields similar to flutriafol at both sites.

\section{Discussion}

This is the first reported study on the efficacy of flutriafol fungicide against sugarcane smut. Our study demonstrated that flutriafol fungicide will provide effective control of smut when applied as spray during planting of sugarcane stalks, a more convenient and practical method. Our study also confirmed that flutriafol fungicide was better than or equally effective as two fungicides registered in Australia (triadimefon and propiconazole) in controlling smut on sugarcane when applied by dipping sugarcane cuttings in fungicide suspension.

The sugarcane smut fungus infects sugarcane plants through buds or germinating shoots and grows in association with the apical and lateral meristems of shoots as they develop (9). Fungicides have been applied by dipping sugarcane cuttings or stalks into suspension of fungicides to protect the buds from infection in the soil (2). The dip treatment ensures that the buds get good coverage for better

Table 4. Efficacy of flutriafol fungicide applied by mixing with fertilizer or spray on cuttings in furrow at planting in experiments 2 and $3^{z}$

\begin{tabular}{|c|c|c|c|c|c|}
\hline \multirow[b]{2}{*}{ Application mode } & \multirow[b]{2}{*}{ Rate (g a.i ha-1) } & \multicolumn{2}{|c|}{ Experiment 2} & \multicolumn{2}{|c|}{ Experiment 3} \\
\hline & & $164 \mathrm{DAI}$ & $\overline{\text { AUDPC }}$ & $187 \mathrm{DAI}$ & $\overline{\text { AUDPC }}$ \\
\hline \multicolumn{6}{|l|}{ Fertilizer mix } \\
\hline & 0 & $28.8 \mathrm{abc}$ & $5,253.8 \mathrm{bc}$ & $49.4 \mathrm{a}$ & $4,836 \mathrm{a}$ \\
\hline & 125 & $23.3 \mathrm{abc}$ & $4,728.4 \mathrm{bc}$ & $11.7 \mathrm{~b}$ & $846 \mathrm{c}$ \\
\hline & 187.5 & $30.9 \mathrm{ab}$ & $5,847.8 \mathrm{ab}$ & $7.8 \mathrm{bc}$ & $638 \mathrm{c}$ \\
\hline & 250 & $24.9 \mathrm{abc}$ & $4,562.5 \mathrm{bc}$ & $4.5 \mathrm{bcd}$ & $419 c$ \\
\hline & 312.5 & $25.3 \mathrm{abc}$ & $5,176.7 \mathrm{bc}$ & $5.1 \mathrm{bcd}$ & $339 \mathrm{c}$ \\
\hline & 375 & $42.4 \mathrm{a}$ & $7,620.3 \mathrm{a}$ & $0.0 \mathrm{~d}$ & $0 \mathrm{c}$ \\
\hline & 500 & $14.8 \mathrm{cde}$ & $3,348.1 \mathrm{~cd}$ & $2.2 \mathrm{~cd}$ & $151 \mathrm{c}$ \\
\hline \multicolumn{6}{|l|}{ Narrow spray } \\
\hline & 0 & $41.3 \mathrm{a}$ & $8,080.6 \mathrm{a}$ & $44.6 \mathrm{a}$ & $3,482 \mathrm{a}$ \\
\hline & 125 & 8.5 ef & $1,893.8 \mathrm{~d}$ & $7.2 \mathrm{bcd}$ & $528 \mathrm{c}$ \\
\hline & 187.5 & $10.0 \mathrm{def}$ & $1,665.8 \mathrm{~d}$ & $0.0 \mathrm{~d}$ & $0 \mathrm{c}$ \\
\hline & 250 & $6.1 \mathrm{f}$ & $1,265.9 \mathrm{~d}$ & $1.7 \mathrm{~cd}$ & $113 \mathrm{c}$ \\
\hline & 312.5 & 8.5 ef & $1,790.0 \mathrm{~d}$ & $1.8 \mathrm{~cd}$ & $46 \mathrm{c}$ \\
\hline & 375 & $6.5 \mathrm{f}$ & $1,320.3 \mathrm{~d}$ & $0.0 \mathrm{~d}$ & $0 \mathrm{c}$ \\
\hline & 500 & $6.4 \mathrm{f}$ & $1,430.3 \mathrm{~d}$ & $0.0 \mathrm{~d}$ & $0 \mathrm{c}$ \\
\hline \multicolumn{6}{|l|}{ Wide spray } \\
\hline & 0 & $20.3 \mathrm{bcd}$ & $4,614.1 \mathrm{bc}$ & $43.8 \mathrm{a}$ & $3,309 \mathrm{~b}$ \\
\hline & 125 & 8.7 ef & $2,183.4 \mathrm{~d}$ & $3.7 \mathrm{~cd}$ & $196 \mathrm{c}$ \\
\hline & 187.5 & 17.8 bcde & $3,425 \mathrm{~cd}$ & $1.5 \mathrm{~cd}$ & $162 \mathrm{c}$ \\
\hline & 250 & $10.3 \mathrm{def}$ & $2,115.6 \mathrm{~d}$ & $0.0 \mathrm{~d}$ & $0 \mathrm{c}$ \\
\hline & 312.5 & 15.4 bcde & $3,441.8 \mathrm{~cd}$ & $0.0 \mathrm{~d}$ & $0 \mathrm{c}$ \\
\hline & 375 & $9.7 \mathrm{def}$ & $1,771.3 \mathrm{~d}$ & $2.0 \mathrm{~cd}$ & $228 \mathrm{c}$ \\
\hline & 500 & 9.7.0 def & $2,039.8 \mathrm{~d}$ & $0.0 \mathrm{~d}$ & $0 \mathrm{c}$ \\
\hline Noninoculated control & $\ldots$ & $6.3 \mathrm{f}$ & $2,260.0 \mathrm{~d}$ & $8.5 \mathrm{bc}$ & $456 \mathrm{c}$ \\
\hline
\end{tabular}


protection (2). The method of fungicide application by dipping sugarcane stalks in fungicide solutions is mostly restricted to propagation nurseries because of logistical problems. We have shown that flutriafol fungicide is an effective alternative in controlling sugarcane smut by adopting a more convenient and practical method of application through existing fungicide sprays on commercial planting machines.

In experiment 3, very low levels of smut were observed in all treatments, even 6 months after fungicide application (187 DAI; Fig. 1B). This experiment was established in summer, and the condition for the development of smut sori and secondary spread was restricted during the cooler months of May and June, even though effectiveness of fungicide ran out after 5 months. In experiment 2 , the conditions were ideal for secondary spread and infection when the effectiveness of fungicide had run out in January and February. This agrees with an earlier study in Australia where fungicides cyproconazole, triadimefon, propiconazole, and azoxystrobin suppressed smut development for 6 months in summer and 9 months in autumn (6). The growth of the sugarcane plants and the growth of the smut fungus are both restricted by temperatures below 20 to $24^{\circ} \mathrm{C}(8)$.

The flutriafol-fertilizer mix was only effective in reducing smut in experiment 3 that was planted in December, when the temperatures after planting ranged from 15 to $35^{\circ} \mathrm{C}$, with a mean of $25^{\circ} \mathrm{C}$. These temperatures provided favorable conditions for rapid germination and root development of sugarcane cuttings. This may have allowed greater uptake of the fungicide by the roots before the smut had fully established infection in the plants. In experiment 2 , the temperature ranged from 7 to $31^{\circ} \mathrm{C}$, with mean of $21^{\circ} \mathrm{C}$ in September. The
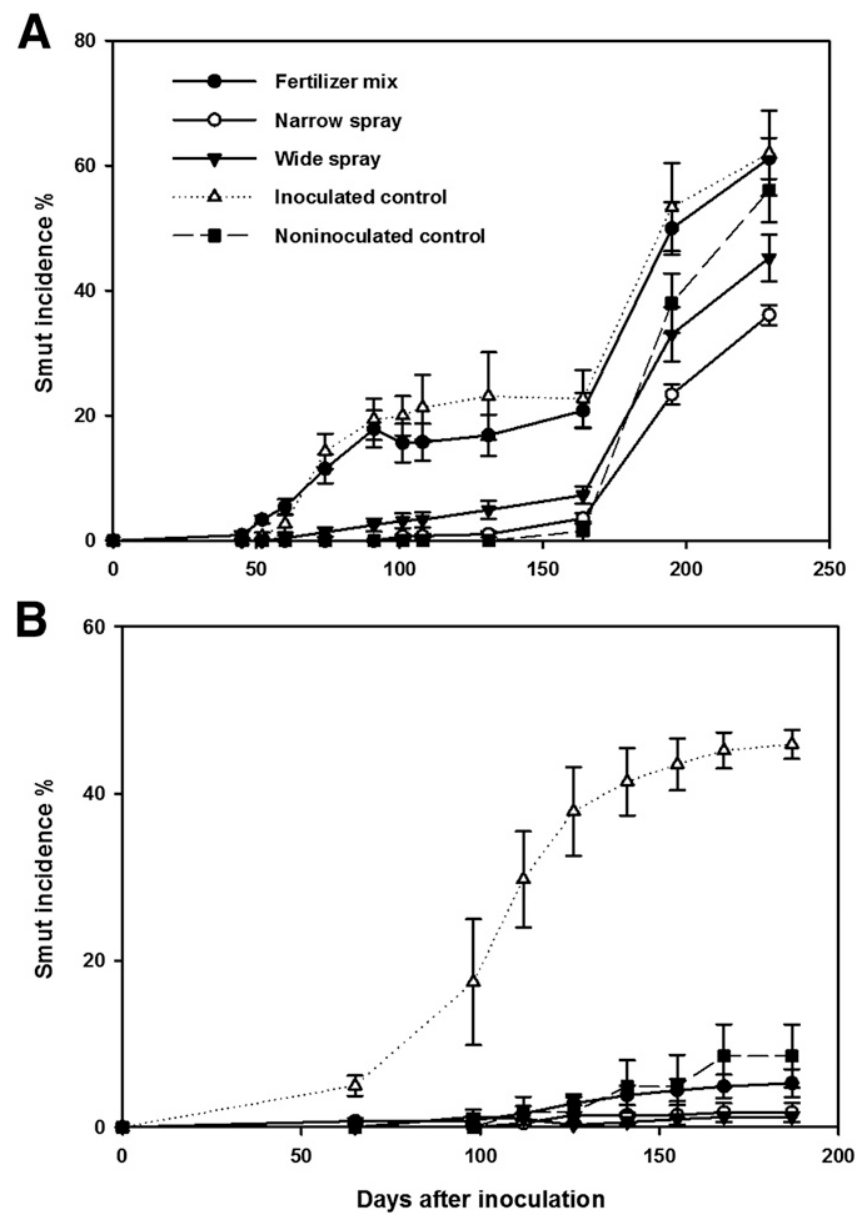

Fig. 1. Development of smut over time on treated and untreated plot of fungicide in A, experiment 2 and B, experiment 3 . Each data point for fertilizer-mix, narrow spray, and wide spray are the mean of seven rates $(0,125,187.5,250,312.5,375$, and $500 \mathrm{~g}$ a.i. $\mathrm{ha}^{-1}$ ) fungicide within each application method. For the noninoculated control, each data point is the mean of five replications. Error bars are the standard error of mean for each data point.

germination and root growth would have been much slower in the cooler conditions in September, and the fungus may have established infection before sufficient fungicide had been taken up by the roots. Other possible causes for the differential response to the flutriafolfertilizer mix between the two experiments could be soil type and microenvironment. The two experiments were established in different soil types: red volcanic soil (experiment 2) and sandy soil (experiment 3). Soil physical or chemical characteristics such as texture, soil moisture, $\mathrm{pH}$, and macro- and microelements and their interaction with the fungicide may have affected fungicide stability or absorption into plant system. Singh (23) reported that absorption of triazole fungicides was highly correlated to soil organic carbon and soil texture. Goring (12) reported the action of a fungicide in soil depends on

Table 5. Efficacy of flutriafol fungicide in controlling sugarcane after spraying with a commercial planter in experiment 4 and experiment 5

\section{AUDPC incidence ${ }^{2}$}

Treatment

Rate (g a.i. ha ${ }^{-1}$ ) Experiment 4 Experiment 5

Inoculated control

Flutriafol

Flutriafol

Flutriafol

Flutriafol

Propiconazole

Noninoculated control

${ }^{\mathrm{z}}$ AUDPC $=$ area under disease progress curve for the whole trial period. Each data point is the mean of five replications. Means within a column followed by the same letter are not significantly different using Fisher's least significant difference test $(P<0.05)$.
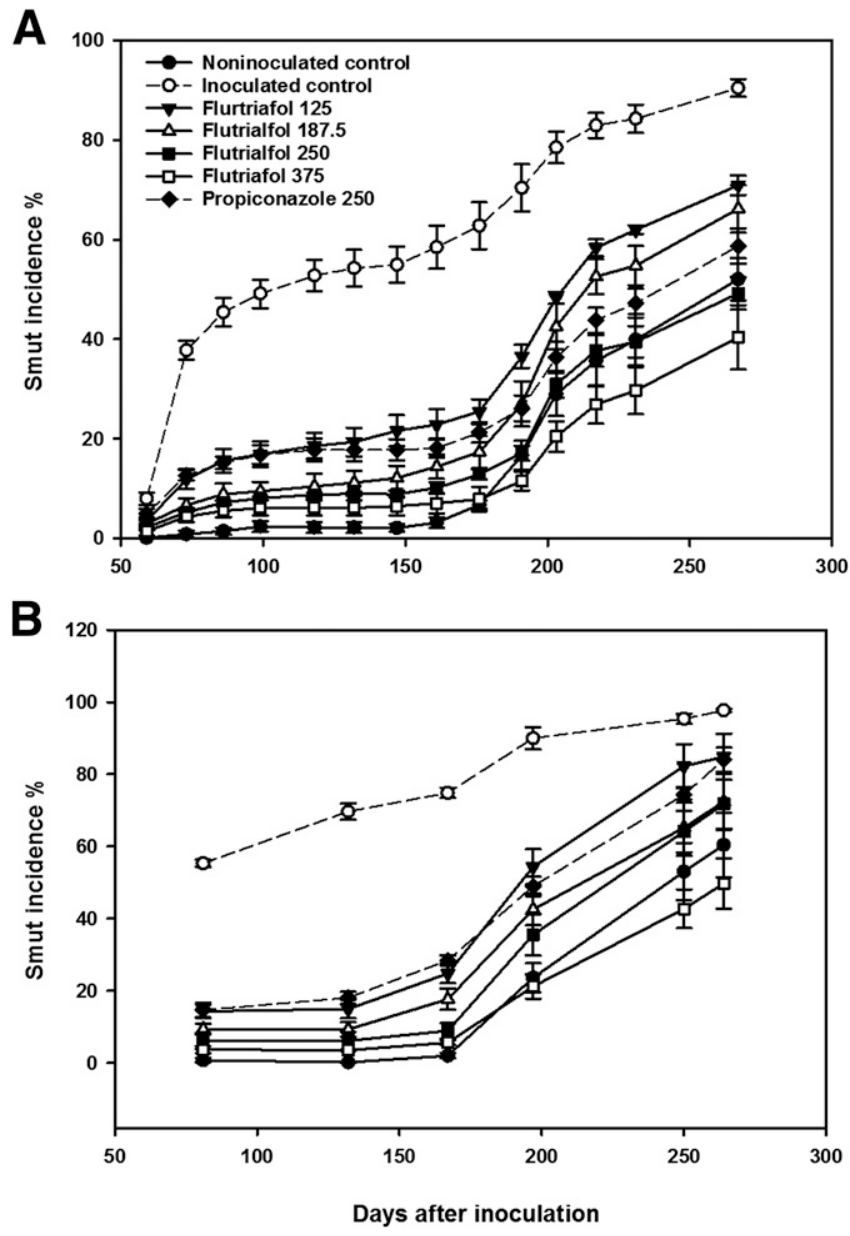

Fig. 2. Smut incidence (\%) over time in fungicide A, experiment 4 and B, experiment 5 in 2010. Each data point is the mean of five replications. Error bars are the standard error of mean. 
(i) vapor pressure, (ii) water solubility, (iii) distribution between soil organic matter and water, (iv) range of degradation constants in soil, and (v) doses required to control various organisms. Our earlier study found that the flutriafol fungicide was effective in controlling pineapple sett rot of sugarcane when applied as a spray directly onto the cuttings but was ineffective when applied as fertilizer-mix (7). A similar phenomenon was reported by Xi et al. (25), where they obtained only marginal control when flutriafol was applied with a fertilizer-mix to control blackleg of canola (Leptosphaeria maculans) in Canada. They postulated that the rapid infection of the pathogen could not be stopped by the flutriafol because of relatively slow fungicide uptake by the roots.

Past research has attempted to find a more practical method of fungicide application for the control of sugarcane smut. Bailey (3) reported substantial control of sugarcane smut by applying triadimefon fungicide to the soil at planting. However, it required very high amounts of fungicide $\left(2 \mathrm{~kg}\right.$ a.i. ha $\left.{ }^{-1}\right)$, which rendered this application method economically nonviable. Bailey (2) reported very little response of carboxin fungicide in controlling sugarcane smut when sprayed on young seedlings. Other work in Zimbabwe (1) compared the efficacy of applying three registered fungicides (triadimefon, triadimenol, and propiconazole) on standing cane prior to cutting the stalks for use as seed-cane. Preplant spray application of standing cane was effective in protecting cuttings from sugarcane smut. However, spraying on standing canes proved to be more laborious than the conventional dip method.

In our experiments, flutriafol provided an estimated 3 to over 6 months of protection from smut infection, depending on time of planting. Sugarcane smut has a latent period within plants of susceptible cultivars of 1.5 to 2 months $(8,16)$. The increase in symptoms after 5 to 6 months in most experiments was due to secondary spread and was observed as smut sori forming on side shoot or tillers. If this infection occurred 1.5 to 3 months prior to symptom expression, then this would suggest that the fungicides protected the plants for 4 to 6 months. However, it is difficult to ascertain the durability of flutriafol in the sugarcane plant tissue or in soil because no information is available. Nevertheless, Yu et al. (27) found that the half-life of flutriafol was 9 to 15 days in wheat plants and 10 to 14 days in soil. The smut incidence increased in the noninoculated control at the same time as the increase in smut incidence in the fungicide-treated plots, which further supports the idea that this infection was due to secondary spread of the disease.
The fungicide treatments with flutriafol and propiconazole gave large increases in cane and sugar yields in experiments 4 and 5. These responses to control of the disease agree with the reported losses from smut in susceptible varieties in other studies $(13,17)$. The yields were much higher in Bundaberg than Mackay, because growing conditions for sugarcane were more favorable in Bundaberg during the trial period. Mackay experienced over 3,000 $\mathrm{mm}$ of rainfall during the trial period, leading to water logging that resulted in poor plant growth and low production. There was a possibility that soilborne diseases such as pineapple sett rot might have affected the trial establishment of Mackay experiments. This is quite unlikely in this case, because our previous work demonstrated that flutriafol is also effective in controlling pineapple sett rots of sugarcane (7). Bundaberg had $1,600 \mathrm{~mm}$ of rainfall, which produced ideal conditions for sugarcane.

This is the first report of the application of the fungicide flutriafol through a commercial whole-stalk sugarcane planter for the control of sugarcane smut. Our results demonstrated that flutriafol is highly effective in protecting sugarcane plants against smut for 4 to 6 months. The inoculation method used in these experiments ensured that smut spores germinated and established infection before the fungicide application. Smut spores germinate and infect within $6 \mathrm{~h}$ of inoculation (8). In experiments 4 and 5, the cuttings were inoculated and incubated for 24 and $48 \mathrm{~h}$, respectively, before fungicide application. The control achieved with the flutriafol indicated that the flutriafol is capable of stopping the fungus in its early stages of establishment in the sugarcane bud. Flutriafol is highly systemic and moves faster in the plant tissue compared with other triazole fungicides $(19,22)$. Our results suggest that the fungicide is not acting purely as a protectant but is taken up by the plants and can stop or slow the fungus that is establishing itself within the sugarcane bud.

Our research has demonstrated that flutriafol applied at rates of $125 \mathrm{~g}$ a.i. $\mathrm{ha}^{-1}$ or above through existing spray equipment on commercial sugarcane whole-stalk planters can protect cuttings from sugarcane smut infection for 4 to 6 months. This method provides similar protection as dip treatments with triadimefon and propiconazole (6).

Previous studies have demonstrated that flutriafol is also effective in controlling pineapple sett rot of sugarcane (7). Thus, there is a potential for this fungicide to be used against both pathogens of sugarcane in one treatment, which would have economic and environmental benefits. The advantages of this application method

Table 6. Cane yield $\left(\mathrm{t} \mathrm{ha}^{-1}\right)$, percentage of commercial cane sugar (CCS), sugar yield $\left(\mathrm{t} \mathrm{ha} \mathrm{h}^{-1}\right)$, and fiber content $(\%)$ in experiment $4^{\mathrm{z}}$

\begin{tabular}{|c|c|c|c|c|c|}
\hline Treatment & Rate (g a.i. ha ${ }^{-1}$ ) & Cane yield & $\mathrm{CCS}$ & Sugar yield & Fiber content \\
\hline Inoculated control & 0 & $81.6 \mathrm{~d}$ & 14.2 & $11.6 \mathrm{~d}$ & 12.0 \\
\hline Flutriafol & 125 & $121.2 \mathrm{ab}$ & 14.4 & $17.5 \mathrm{ab}$ & 11.9 \\
\hline Flutriafol & 187.5 & $116.3 \mathrm{bc}$ & 14.6 & $16.9 \mathrm{bc}$ & 12.2 \\
\hline Flutriafol & 250 & $119.9 \mathrm{~b}$ & 14.7 & $17.6 \mathrm{ab}$ & 12.2 \\
\hline Flutriafol & 375 & $132.3 \mathrm{a}$ & 14.4 & $19.1 \mathrm{a}$ & 12.3 \\
\hline Propiconazole & 250 & $119.8 \mathrm{~b}$ & 14.5 & $17.4 \mathrm{ab}$ & 12.2 \\
\hline Noninoculated control & - & $104.7 \mathrm{c}$ & 14.6 & $15.3 \mathrm{c}$ & 12.0 \\
\hline
\end{tabular}

${ }^{\mathrm{z}}$ Each data point is the mean of five replications. Means within a column followed by the same letter are not significantly different using Fisher's least significant difference test $(P<0.05)$.

Table 7. Cane yield $\left(\mathrm{t} \mathrm{ha}^{-1}\right)$, percentage of commercial cane sugar (CCS), sugar yield $\left(\mathrm{t} \mathrm{ha}{ }^{-1}\right)$, and fiber content (\%) in experiment $5^{\mathbf{z}}$

\begin{tabular}{lccccc}
\hline Treatment & Rate $\left(\mathbf{g}\right.$ a.i. $\left.\mathbf{~ h a}^{-\mathbf{1}}\right)$ & Cane yield & CCS & Sugar yield & Fiber content \\
\hline Inoculated control & 0 & $18.7 \mathrm{c}$ & $15.2 \mathrm{~b}$ & $2.8 \mathrm{~d}$ & 12.0 \\
Flutriafol & 125 & $46.3 \mathrm{~b}$ & $15.5 \mathrm{ab}$ & $7.2 \mathrm{c}$ & 1.8 \\
Flutriafol & 187.5 & $48.3 \mathrm{ab}$ & $15.9 \mathrm{a}$ & $8.7 \mathrm{abc}$ & 12.0 \\
Flutriafol & 250 & $53.3 \mathrm{ab}$ & $16.0 \mathrm{a}$ & $7.9 \mathrm{abc}$ & 11.9 \\
Flutriafol & 375 & $49.0 \mathrm{ab}$ & $16.1 \mathrm{a}$ & $7.4 \mathrm{bc}$ & 11.9 \\
Propiconazole & 250 & $46.5 \mathrm{~b}$ & $15.9 \mathrm{a}$ & 1.9 & $\mathrm{a}$ \\
Noninoculated control & - & $54.3 \mathrm{a}$ & $16.0 \mathrm{a}$ & 12.1 \\
\hline
\end{tabular}

$\overline{\mathrm{z}}$ Each data point is the mean of five replications. Means within a column followed by the same letter are not significantly different using Fisher's least significant difference test $(P<0.05)$. 
over a dip treatment are: (i) no need for disposal of waste fungicide from the large fungicide dip tanks (5,000 to 10,000 liters of fungicide solution); (ii) no extra cost for capital expenditure on large dip tanks; (iii) combined control of smut and pineapple sett rot, which will reduce overall fungicide use and cost; and (iv) a more practical application method that will allow treatment of more stages of the propagation of sugarcane cuttings and improve control of sugarcane smut.

Our experiments were conducted with the highly susceptible Q205 ${ }^{\mathrm{A}}(5)$. This cultivar has been withdrawn from commercial production because of smut. The fungicide may provide greater protection in moderately susceptible cultivars. Sugarcane is a perennial or multiyear crop, where plant crops are harvested and regrown as ratoon crops for 3 to 7 years. It is not clear from this study whether the protection from smut could carry over to the ratoon crop. Further investigations are warranted to understand the efficacy of the flutriafol fungicide on moderately susceptible cultivars and on ratoon crops. The sugarcane smut fungus invades all meristem tissue, and traces of fungal hyphae are found in nodal tissue when plants are fully systemically infected. Our research suggested that flutriafol can stop smut from establishing infection after infection has commenced. Future research should determine whether the commercial spray treatment can cure systemically infected stalks of moderately susceptible cultivars. A treatment that could cure systemically infected cuttings would have even wider applications for the management of sugarcane smut.

\section{Acknowledgments}

We thank Crop Care Australasia for financial support (project number 1952250; the flutriafol fungicide Sinker is a registered trademark of Crop Care Australasia Pty Ltd.); E. Deomano for statistical advice; and R. James, G. Bade, D. Taylor, and L. Meagher for technical assistance.

\section{Literature Cited}

1. Anonymous. 1995. Pages 44-49 in: Research Report 1994 and 1995. Zimbabwe Sugar Association Experiment Station, Zimbabwe.

2. Bailey, R. A. 1980. Possibilities for the control of sugarcane smut (Ustilago scitaminea) with fungicides. S. Afr. Sugar J. 1980:158-164.

3. Bailey, R. A. 1983. The effect of soil and seedcane application of triadimefon on the incidence of sugarcane smut (Ustilago scitaminea). Pages 99-104 in: Proc. S. Afr. Sugar Technol. Assoc.

4. Ballinger, D. J., and Kollmorgen, J. F. 1988. Effect of the triazole coated superphosphate applied at sowing on take-all and yield of wheat. Aust. J. Exp. Agric. 28:635-638.

5. Bhuiyan, S. A., Croft, B. J., Cox, M. C., and Bade, G. 2010. Varietal resistance of sugarcane to natural infection of smut - preliminary results. Proc. Aust. Soc. Sugar Cane Technol. 32:355-365.

6. Bhuiyan, S. A., Croft, B. J., James, R. S., and Cox, M. C. 2012. Laboratory and field evaluation of fungicides for the management of sugarcane smut caused by Sporisorium scitamineum in seedcane. Australas. Plant Pathol. 41:591-599.
7. Bhuiyan, S. A., Croft, B. J., and Tucker, G. R. 2014. Efficacy of the fungicide flutriafol for the control of pineapple sett rot of sugarcane in Australia. Australas. Plant Pathol. 43:413-419.

8. Bock, K. R. 1964. Studies on sugarcane smut (Ustilago scitaminea) in Kenya Trans. Br. Mycol. Soc. 47:403-407.

9. Comstock, J. C. 2000. Smut. Pages 181-185 in: A Guide to Sugarcane Diseases. P. Rott, R. A. Bailey, J. C. Comstock, B. J. Croft, and A. S. Saumtally, eds. CIRAD and ISSCT, Montpellier, France.

10. Croft, B. J., and Braithwaite, K. S. 2006. Management of an incursion of sugarcane smut in Australia. Australas. Plant Pathol. 35:113-122.

11. Croft, B. J., Magarey, R. C., Allsopp, P. G., Cox, M. C., Willcox, T. G., Milford, B. J., and Wallis, E. S. 2008. Sugarcane smut in Queensland: Arrival and emergency response. Australas. Plant Pathol. 37:26-34.

12. Goring, C. A. I. 1967. Physical aspects of soil in relation to the action of soil fungicides. Annu. Rev. Phytopathol. 5:285-317.

13. Hoy, J. W., Hollier, C. A., Fontenot, D. B., and Grelen, L. B. 1986. Incidence of sugarcane smut in Louisiana and its effect on yield. Plant Dis. 70:59-60.

14. Kenward, M. G., and Roger, J. H. 1997. Small sample inference for fixed effects from restricted maximum likelihood. Biometrics 53:983-997.

15. Khangura, R. K., and Barbetti, M. J. 2002. Efficacy of Impact ${ }^{\circledR}$ to manage blackleg (Leptosphaeria maculans) in canola. Aust. J. Agric. Res. 53:311-321.

16. Lee-Lovick, G. 1978. Smut of sugarcane-Ustilago scitaminea. Rev. Plant Pathol. 57:181-188.

17. Magarey, R. C., Bull, J. I., Sheahan, T., and Denney, D. 2010. Yield losses caused by sugarcane smut in several crops in Queensland. Proc. Aust. Soc. Sugar Cane Technol. 32:347-354.

18. Mebalds, M. I., and Price, T. V. 2008. Chemical control of blind seed disease in perennial ryegrass (Lolium perenne) in Victoria. Australas. Plant Pathol. 37: 148-153.

19. Metcalfe, R. J., Shaw, M. W., and Russell, P. E. 2000. The effect of dose and mobility on the strength of selection for DMI fungicide resistance in inoculated field experiments. Plant Pathol. 49:546-557.

20. Saxton, A. M. 1998. A macro for converting mean separation output to letter groupings in Proc Mixed. Pages 1243-1246 in: Proc. 23rd SAS Users Group Int. Nashville, TN. SAS Institute, Cary, NC.

21. Shaner, G., and Finney, R. E. 1977. The effect of nitrogen fertilization on the expression of slow-mildewing resistance in Knox wheat. Phytopathology 67 1051-1056.

22. Shephard, M. C. 1985. Fungicide behaviour in the plant: Systemicity. Pages 99-106 in: Fungicides for Crop Protection. BCPC Monogr. No. 31. I. M Smith, ed. BCPC Publication, Croydon, UK

23. Singh, N. 2002. Sorption behavior of triazole fungicides in Indian soils and its correlation with soil properties. J. Agric. Food Chem. 50:6434-6439.

24. Stoll, M., Piepenbring, M., Begerow, D., and Oberwinkler, F. 2003. Molecular phylogeny of Ustilago and Sporisorium species (Basidiomycota Ustilaginales) based on internal transcribed spacer (ITS) sequences. Can. J. Bot. 81:976-984.

25. Xi, K., Kutcher, H. R., Westcott, N. D., Morrall, R. A. A., and Rimmer, S. R. 1991. Effect of seed treatment and fertilizer coated with flutriafol on blackleg of canola (oilseed rape) in western Canada. Can. J. Plant Pathol. 13:336-346.

26. Xu, X. M., and Ridout, M. S. 1998. Effects of initial epidemic conditions, sporulation rate, and spore dispersal gradient on the spatio-temporal dynamics of plant disease epidemics. Phytopathology 88:1000-1012.

27. Yu, P., Jia, C., Song, W., and Liu, F. 2012. Dissipation and residues of flutriafol in wheat and soil under field conditions. Bull. Environ. Contam. Toxicol. 89:1040-1045. 